\title{
Exploration on Improving the Quality of Continuing Education Teaching
}

\author{
Xinxiu Wen \\ College of Information Science and Engineering \\ East China University of Science and Technology \\ Shanghai, China \\ wenxinxiu@ecust.edu.cn
}

\author{
Zeping Yang, Zhanquan Wang \\ College of Information Science and Engineering \\ East China University of Science and Technology \\ Shanghai, China \\ \{yangzeping, zhqwang\}@ecust.edu.cn
}

\begin{abstract}
With the rapid development of the Internet technology, it is imperative to reform current curriculum plan and traditional teaching mode to meet the information requirements of the times and improve teaching quality of continuing education. The paper analyzes the problems on course of Web design which is offered by the School of Continuing Education in East China of University of Science and Technology, and introduces the reform and exploration on the course based on aspect-oriented course design, task-driven classroom teaching, rich and diverse resource sharing and various forms of teaching assessment. The aims are to cultivate students' abilities of computation thinking and improve students' abilities of analyzing problems and solving problems. The teaching practice proves that the exploration is feasible and effective.
\end{abstract}

Keywords-computational thinking; Web design; aspect_orientation; continuing education; course reform

\section{INTRODUCTION}

The strategic themes of National Education Reform and Development of Long-term Planning Programs (2010-2020) put forward to accelerate the development of continuing education, establish institutional mechanisms for continuing education and build a flexible and open system of lifelong education [1]. In accordance with the requirements of the strategic themes, the School of Continuing Education in East China University of Science and Technology (ECUST) sets up a series of computer fundamental education courses in recent years, which help students solve the problems in their work successfully and cultivate many qualified workers meeting the needs of the country. However, in the long period practice of teaching and learning, we found there are some problems must be solved combined with the characteristics of continuing education students: some knowledge taught is out of date, theoretical teaching is divorced from professional application, teaching method which takes teachers as the main body is difficult to play the initiative of students, etc. Information Science \& Technology in China--A Roadmap to 2050 proposes that cultivating students' abilities of computational thinking during the teaching of computer fundamental courses is the effective way to overcome the "narrow tool theory", which is the basis of solving the problems of other information technology [2]. Computational thinking is using abstraction and decomposition when attacking a large complex task or designing a large complex system. It is separation of concerns. It is choosing an appropriate representation for a problem or modeling the relevant aspects of a problem to make it tractable [3]. Therefore, it is necessary to reform the current computer fundamental courses setting and exploration on new teaching mode for continuing education students in ECUST.

Conforming to the general trend of the times, Web design course is the first computer course for various professions in the School of Continuing Education in ECUST and its teaching effect is closely related to students' interest for subsequent computer courses. Taking Web design course as subject investigated and computational thinking ability as cultivating objective, our team (all of us have been computer teachers in ECUST for ten years ) tries to use aspect-oriented course design, task-driven classroom teaching, rich and diverse resource sharing and various forms of classroom assessment to form the teaching mode of taking students as the main body and taking teacher as the leading, to improve students' professional abilities, innovation and practice abilities, and enhance students' abilities of computational thinking.

The remainder of this paper is organized as follows. Section 2 presents the related work. Section 3 introduces course reform program. Conclusions are presented in Section 4.

\section{RELATED WORK}

There are many works on cultivation of computational thinking and teaching of continuing education in recent years. In [4], Qualls and Sherrell illustrate some important work conducted in an effort to incorporate computational thinking into curricula. Recent recognition by the National Science Foundation proves that computational thinking is an important component for education and society and deserves immediate attention. In [5], Yadav et al describe the implementation and evaluation of a computational thinking module in a required course for elementary and secondary education majors. Their results suggest that given relevant information about computational thinking, education students' attitudes toward computer science becomes more favorable and they are more likely to integrate computing principles in their future teaching. In [6], Davies proposes an approach which separates problem solving from language teaching in introductory programming courses and compares the approach with a traditional languagebased pedagogy. The result reveals that students' comfort level with modularity (writing functions) is increased. In [7], Rüütmann and Kipper introduce the qualitative research results of the analysis of the designed learner-centered program for 
continuing education of technical teachers. The aim is to evaluate the quality of the curriculum and the quality of teaching in order to improve and enhance the curriculum for continuing education of technical teachers. Therefore, for continuing education students in ECUST, it is beneficial to optimize the current course plan, introduce computational thinking and update teaching method to improve students' interest of study and enhance the quality of teaching.

\section{COURSE REFORM PROGRAM}

Most continuing education students are adults. Having faced the social pressure, they are eager to master professional technology and pay less attention to computer fundamental knowledge. Some of them take computer as an easy tool due to lack of deep understanding about computer science. According to these students' characteristics, how to help students solve the professional problems using computer and improve their realization to computer science at the same time, train students' abilities of solving problems and computational thinking are our practical problems and research subject.

\section{A. Curriculum module settings}

Web design course is the first computer course for students in the School of Continuing Education in ECUST. In our reform plan, the teaching objectives of course are to improve the students' realization to computer science, cultivate students' abilities of computational thinking, master the skills of website design and build solid foundation for successive courses. The course includes 34 theoretical class hours and 34 experimental class hours. The teaching contents include theoretical foundation of Internet, plan and design of website, layout and optimization of web pages, design and processing of image, production and release of animation, simple programming of script, etc. Upon completion of this course, students should be able to:

- Mastering the layered structure and basic working principle of Internet.

- Adopting Dreamweaver to design website and optimize webpage.

- Using Photoshop to beautify the whole webpage effect of website.

- Utilizing Flash to make the various animations in the website.

- Making use of script language to realize the script programming.

Having finished the course, students may attend voluntarily the exam organized by shanghai municipal labor and social security bureau vocational skills identification center, Examination qualified students will attain the level four certification of Web designer, which is helpful for students' job searching and job keeping.

\section{B. Curriculum reform plan}

Just like reading, writing, and arithmetic, computational thinking will be a fundamental skill used by everyone in the world by the middle of the 21st Century [3]. In our course reform, teachers put the definition and basic characteristics (abstraction, automation, reduction, etc.) of computational thinking into class learning and explain these knowledge points by case teaching, which could help students understanding the importance of computer science and motivate students' interest of study. For example, it's very difficult for students to understand two kinds of computer architectures: OSI/RM and TCP/IP. Teachers take QQ and E-mail as the examples, abstract the basic characteristic of network structure and simplify the complex concepts, which improve the understanding abilities of students.

The curriculum reform plan is developed as follows:

\section{1) Aspect-oriented course design}

To ensure students have whole and clear cognitions to the course at the beginning of semester, teacher plan the course based on aspect-oriented technology in advance [8]: setting the functional knowledge points as core knowledge points, and abstracting key points which crosses the whole course as crosscutting points. Teachers point out its position in the whole course and the relationship with other knowledge points when teaching some knowledge points, which could realize the effective connection between the selected knowledge point and other knowledge points before or after it. For example, in the Web design course, three kinds of classical websites are introduced and showed in the first class: enterprise class website, shopping class website and teaching class website, and the key crosscutting points inside three websites are extracted: three kinds of websites use CSS+DIV to layout the websites and adopt PHOTOSHOP to realize the slice processing (Fig. 1) By this means, students not only have clear understanding about the whole course, but also understand some important characteristics of computational thinking (abstraction, decomposition ), which would help them pay more attention on the course.

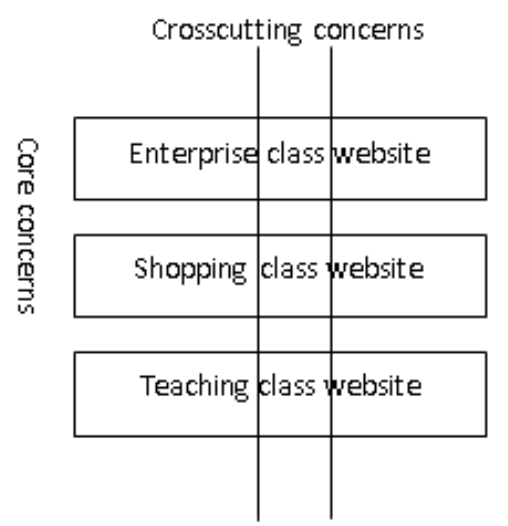

Fig. 1. Web design course example based on aspect-oriented

\section{2) Task-driven classroom teaching}

It is necessary to lay down appropriate teaching method according to continuing students' characteristics. To improve the classroom teaching effect, task-driven teaching method is adopted. Teachers prepare actual examples which are related to course knowledge points, students are told the actual problems would be solved at the beginning of each class, and 
then the related teaching contents are introduced. In the end of class, students are asked to solve the problems using the learned knowledge. By this way, students have clear study object in every class and follow the teacher earnestly. Naturally, the passive learning is changed as active learning. For example, in the Web design course, before introducing the Flash technology on animation, we play the movie prelude first and tell students that is our task in the class. Furthermore, we teach students produce frame animation. Having taught the related knowledge points, students are asked to answer how to realize the movie prelude with the help of what they have studied. Students are initiated from the beginning of the class, and they would listen to the teacher seriously and answer the question positively. The task-driven method improves students' abilities of analyzing problems and solving problems.

\section{3) Rich and diverse resource sharing}

Because most continuing students are workers, some students couldn't assure attendance due to business trip or work overtime. To ensure all students could attain the course resources, the School of Continuing Education in ECUST has built a special teaching resources website: Teaching videos, courseware and electronic books are uploaded into teaching website, students could access to all course resources in their spare time. Besides, to ensure students' homework could be corrected by teacher timely, homework uploading system is built to save and document students' exercise and homework. In the end, to ensure the real-time contact between teacher and students, course QQ group is set up and students' questions could be answered timely. By providing different ways of resource sharing, efficiency of work and quality of teaching are improved mostly.

\section{4) Various forms of teaching assessment}

To master students' learning effect periodically, it is required that students should be tested having finished the study of a unit. The ways of test have many kinds: Teaming to answer questions, completing the assigned task on the computer, etc. These ways not only encourage students to review the contents of the study timely but also release teachers' burden from marking. Considering the practicality of computer knowledge, a special homework is set which ask two or three students to finish a website design task according to their profession or interest. After all teams completed the task, there are mutual evaluations among the students. During the process of mutual evaluations, students could realize the advantages and problems of their own works, and make clear the direction of their efforts. In the final exam, in addition to the traditional test module (about $80 \%$ percent), the other (about $20 \%$ percent) is freely design, which asks students to solve a concrete question in profession or work. The above assessment methods not only enhance students' abilities of solve practical problems but also improve the qualities of personnel training.

\section{CONCLUSIONS}

Course reform on continuing education is the demand of the information society. Most continuing students are very clear about their learning goals and eager to update their knowledge structure. As the first computer course in the School of Continuing Education in ECUST, Web design course is very important for promoting students' computational thinking abilities and helping them solve professional problems. Adopting aspect-oriented course design, task-driven classroom teaching, rich and diverse resource sharing and various forms of teaching assessment, teaching effect has been improved rapidly. Most students not only pass the final exam successfully but also attain the level four certification of Web designer awarded by shanghai municipal labor and social security bureau vocational skills identification center. Moreover, students' abilities of analyzing and solving problems are enhanced, which build a good foundation for further computer course study.

\section{REFERENCES}

[1] Ministry of Education of the people's Republic of China. National education reform and development of long-term planning programs (2010-2020). 2010,7.

[2] Chinese Academy of Sciences. Information Science \& Technology in China--A Roadmap to 2050. science press, 2009,9

[3] Wing J M. Computational Thinking. Communication of the ACM, 2006, 49(3): 33-35.

[4] Qualls J A, Sherrell L B. Why Computational Thinking Should Be Integrated Into The Curriculum. Journal of Computing Sciences in Colleges, 2010, (5):66-71

[5] Yadav A, Zhou N. Mayfield C. Introducing Computational Thinking in Education Courses. In SIGCSE'11, March 9-12, 2011, Dallas, Texas, USA.

[6] Davies S. The Effects Of Emphasizing Computational Thinking In An Introductory Programming Course. Frontiers in Education Conference, 2008. FIE 2008. 38th Annual. 2008:T2C-3-T2C-8.

[7] Rüütmann T, Kipper H. Analysis of the Program for Continuing Education of Technical Teachers on the Basis of Graduates' Feedback Results. 2014 International Conference on Interactive Collaborative Learning. 03-06 December 2014, Dubai, UAE

[8] Kiczales G, Lamping J, Mendhekar A, et al. Aspect-Oriented Programming. Proceedings of the 1997 European Conference on ObjectOriented Programming. 1997, 220-242. 